\title{
Performance Over Enjoyment? Effect of Game-Based Learning on Learning Outcome and Flow Experience
}

\author{
Kevin Chan ${ }^{1 *}$, Kelvin Wan $^{2}$ and Vivian King ${ }^{3}$ \\ ${ }^{1}$ Department of Applied Social Sciences, The Hong Kong Polytechnic University, Kowloon, Hong Kong, ${ }^{2}$ Center for Holistic \\ Teaching and Learning, Hong Kong Baptist University, Kowloon, Hong Kong, ${ }^{3}$ Department of Social Work and Social \\ Administration, The University of Hong Kong, Hong Kong
}

\section{OPEN ACCESS}

Edited by:

Mark Andrew Pegrum,

University of Western Australia, Australia

Reviewed by:

Johanna Hall,

The Open University, United Kingdom

Nashwa Ismail,

The Open University, United Kingdom

*Correspondence:

Kevin Chan

sskevin@polyu.edu.hk

Specialty section:

This article was submitted to Digital Learning Innovations,

a section of the journa

Frontiers in Education

Received: 29 January 2021 Accepted: 07 May 2021

Published: 07 June 2021

Citation:

Chan K, Wan K and King V (2021) Performance Over Enjoyment? Effect of Game-Based Learning on Learning

Outcome and Flow Experience. Front. Educ. 6:660376.

doi: 10.3389/feduc.2021.660376
Competitiveness in serious games and game-based learning contexts, have been suggested to be associated with variations in flow experience pertaining from game experience. Evidence from the game-based learning literature suggested that gamebased learning in general enhances learning outcomes, and applicable to learning psychology at the undergraduate level. Yet the magnitude of such effect remains mixed from empirical evidence. The current study examines whether game-based learning, in competitive and non-competitive game format, would lead to differentiated gains on learning outcomes, perceived flow experience from game-based learning, and their interaction. We wish to test whether competitive and non-competitive formats of game-based learning could be characterized with different configurations of game flow experience that encapsulate the game-based learning experience, as well as the extent to which such predominant game flow experience would correlate with observed learning outcomes from featured gamebased learning conditions. Effect of game-based learning was tested with an $2 \times 2$ experimental design. Participating learners $(n=142)$ were randomly assigned into either one out of four experimental conditions based on a $2 \times 2$ block design with two independent variables, competitiveness of game-based learning (competitive vs. non-competitive), and format of game-based learning (group vs. individual). Participating Learners in each of the conditions were assessed on learning outcomes related to the subject matters intended for the game-based learning artefacts. Results on learning outcomes revealed a significant main effect of competitiveness of game-based learning was observed, but not for format nor interaction effect. Main effect of format of game-based learning when learning in groups was observed from another two-way ANOVA analysis in a finite set of eGameFlow constructs including feedback, autonomy, goal clarity, and social interaction. Interaction effects between competitiveness of game-based learning and format was observed in autonomy and goal clarity constructs. Results from this study suggested that competitiveness and group format does not necessarily warrant improvement on learning outcomes in the game-based learning context. Main effects on cognitive flow dimensions align with the performance orientation among Asian learners. Further research would shed light on identifying levels of optimal gamified elements while assuring improvement on intended learning outcomes in the Asian tertiary education context. 


\section{INTRODUCTION}

\section{Background}

Learners' engagement in the 21 st century is critical with increasing prevalence of blended and remote learning, and one of the popular pathways is to engage learners with gamebased learning. Recently, game-based learning has been demonstrated, with comprehensive evidence from education research (Plass et al., 2015) to neuroscience (Howard-Jones and Jay, 2016), to augment learning. Such enhancement on learning has been reviewed and suggested that game-based learning enhances learning performance and outcomes through affective (e.g., enjoyment), cognitive (e.g., cognitive load), and behavioral (e.g., intention to participate in learning) mechanisms (Koivisto and Hamari, 2019; Sailer and Homner, 2019).

In the context of learning of psychology at the undergraduate level, game-based learning has been widely applied and evaluated across various sub-disciplines, including history of psychology (Abramson et al., 2009; Berrenberg and Prosser, 1991), general/introductory psychology (Paul et al., 2006), organizational psychology (Stansbury and Earnest, 2017), and neuropsychology (Goldey and Espinosa, 2020). Most of these attempts employed trivia and board game style for engaging learners with game-based learning toward knowledge mastery.

Though these empirical evaluations examined efficacy of game-based learning in the learning of psychology context, the mechanism for understanding arousal and engagement in gamebased learning itself is also a worthwhile venture among researchers in learning and education. The flow theory is deemed a fittingly effective model in understanding how learners engage with game-based learning.

Originated from positive psychology, the flow theory (Nakamura and Csikszentmihalyi, 2014) describes general positive experience in life with absorption from what one does, including the process of gaming or learning, that ultimately contributes to our wellbeing.

Transplanted to the game-based learning context, flow theory has been widely applied for understanding how learning through games approximates flow and peak experience that allow learners to be absorbed in the game-based learning experience and arrive at enhanced learning outcomes thereafter (Kasurinen and Knutas, 2018; Koivisto and Hamari, 2019; Reiners and Wood, 2015; Sweetser and Wyeth, 2005; Terras and Boyle, 2019). Competitive games, in both serious games and game-based learning contexts, have been suggested to be associated with variations in flow experience pertaining from game experience, including challenge (Cairns, 2016), feedback on learning (Chapman and Rich, 2018), as well as autonomy and social relatedness (Sailer et al., 2017).

While recent research on game-based learning and flow theory mainly describe flow in the game-based learning context (Hamari and Koivisto, 2014; Sedig, 2007; Hou, 2015; Shin, 2006) or modeling game flow as a determinant of subsequent learning performance gains (Hamari et al., 2016; Chang et al., 2017; Erhel and Jamet, 2019), the extent to which competitiveness (Kiili, 2005; Nah et al., 2014; De-Marcos et al., 2016; Sailer et al., 2017; Licorish et al., 2018) in game-based learning exert influence on the learning process and subsequent learning performance and outcome remains inconclusive and warrant further explorations.

Conclusions from recent advances in game-based learning literature suggested that the degree to which game-based learning enhances learning outcomes have been generally positive. Yet the magnitude of such effect remains mixed from empirical evidence.

In a recent meta-analysis of game-based learning evaluations on 45 empirical studies, Sailer and Homner (2019) revealed that effect size game-based learning was statistically significant although small and varied with types of learning outcomes. Studies on behavioral learning outcomes such as surgical or spatial skills yielded the lowest mean effect size with Hedge's $g$ of 0.25 while studies on cognitive learning outcomes of gamebased learning such as mastery of conceptual and applied knowledge yielded the highest mean effect size with Hedge's $g$ of 0.75 (Sailer and Homner, 2019).

Nonetheless, recent evidence converged to the argument that flow components such as perceived challenge, perceived autonomy, immersion from game experience could be potentially universal determinants toward effective game-based learning.

With a dearth of empirical investigations in flow of gamebased learning, particularly in the learning of psychology context, we wish to explore whether game-based learning, apart from achieving its educational goals, would elicit affective outcomes in learners as proposed in the flow theory that precipitate engagement and subsequent enhancement in learning.

Specifically, we wish to address three research questions in the current study:

What is the relationship between learning format (i.e., solitary vs. collaborative game-based learning) and game flow experience?

What is the relationship between competitiveness of gamebased learning (i.e., competitive vs. non-competitive gamebased learning) on game flow experience?

Is there any interaction effect(s) on game flow experience between learning format and competitiveness?

\section{MATERIALS AND METHODS}

Toward providing a comprehensive and transparent disclosure of game-based learning artefacts and procedures adopted in this study, reporting of game-based learning featured in this experiment conforms to the Guideline for Reporting Evidencebased practice Educational interventions and Teaching (GREET) (Phillips et al., 2016):

GREET01: Intervention - Provide a brief description of the educational intervention for all groups involved [e.g., control and comparator(s)] 
TABLE 1 | The $2 \times 2$ factorial design on the competitiveness and format of game-based learning.

Competitiveness/format

Competitive (cell game)

Non-competitive (WISC)
Individual-based

Individual-cell game $(N=36)$

Individual-WISC $(N=36)$
Group-based

Group-cell game ( $N=33)$

Group-WISC (N = 37)
We conducted a randomized controlled trial to compare effects of game-based learning interventions for learning psychology among undergraduate learners at a university in Hong Kong.

Effect of game-based learning was examined with a $2 \times 2$ factorial design with two independent variables: competitiveness of game-based learning and format of game-based learning (see Table 1).

Competitiveness of game-based learning was manipulated by introducing two game-based learning artefacts for learning about motivation in psychology.

Formats of game-based learning were manipulated with participants randomly assigned to group game-based learning or individual game-based learning. In group game-based learning, learners were assembled physically in a face-to-face small group for engaging in game-based learning activities. In the individual game-based learning condition, learners engaged in game-based learning activities without simultaneous interactions with other learners on the same task.

GREET02: Theory - Describe the educational theory (ies), concept or approach used in the educational intervention

Affective outcomes derived from game-based learning was assessed with the eGameFlow model, a 42-item 7-level likert scale instrument soliciting game flow experience of learners on eight dimensions: immersion, social interaction, challenge, goal clarity, feedback, concentration, autonomy, and knowledge improvement (Fu et al., 2009). This instrument evaluates educational games by incorporating six elements of flow in immersion, challenge, goal clarity, feedback, concentration, autonomy (Csikszentmihalyi, 2014) with two additional learning artifices in social interaction and knowledge improvement (Sweetser and Wyeth, 2005). The eGameFlow instrument demonstrated good to excellent internal reliability (0.81-0.93), and convergent validity across eight dimension subscales as well as criterion validity by correlating eGameFlow scores with a visual-analogue scale on overall enjoyment from game-based learning.

GREET03: Learning Objectives - Describe the learning objectives for all groups involved in the educational intervention

Game-based learning activities were introduced to determine whether game-based learning improves i) objective knowledge of motivation in psychology, ii) ability to utilize this knowledge in application toward problem solving related to understanding of human motivations, and iii) affective outcomes from game-based learning including immersion, arousal from challenge, and arousal from heightened social interaction during the course of game-based learning.

GREET04: Evidence-Based Practice (EBP) Content List the foundation steps of EBP (ask, acquire, appraise, apply, assess) included in the educational intervention

Game-based learning in this study aligns to the evidence-based practice framework with mostly knowledge acquisition about human motivation for future applications in human services, business planning, and engineering designs where applicable.

GREET05: Materials - Describe the specific educational materials used in the educational intervention. Include materials provided to the learners and those used in the training of educational intervention providers. Indicate where these can be accessed (e.g., online appendix, URL)

\section{Game-Based Learning Artefacts}

The "Cell Game" (http://palms.polyu.edu.hk/educational-apps/ cell-game/) is a turn-base strategic game-based learning platform that features salient competitive game-based learning activities. In this territory game format, learners compete with each other or in teams to earn points and expand their territories on the leaderboard as reward. Points for gaining or losing territory on the game board in Cell Game were determined by correct response on questions pertaining to the subject content matter.

The WISC-Online platform (https://www.wisc-online.com) features user-built board games for customized development of game-based learning artefact, with a set of non-competitive board game-based learning artefacts developed specifically for this experiment.

The researcher created and collected 166 assessment questions related to the learning module on motivation. Levels of difficulty of assessment questions in this study were based on the Bloom Taxonomy guidelines (Anderson et al., 2001), with items constructed toward assessing basic learning outcomes, such as remembering and understanding, to higher level outcomes, such as applying and analyzing subject content matters on human motivation.

GREET06: Educational Strategies: Describe the teaching/learning strategies (e.g., tutorials, lectures, online modules) used in the educational intervention.

A set of 6 board games related to theories and concepts of motivation were developed on the WISC-Online platform in the following format: crossword puzzles, "Jeopardy" type Q\&A game, 
TABLE 2 | Summary table of the selected WISC-Online Games.

\begin{tabular}{|c|c|c|c|c|c|}
\hline \multirow{2}{*}{$\begin{array}{l}\text { Name } \\
\text { Crossword }\end{array}$} & \multicolumn{3}{|c|}{ Players questions types } & \multirow{2}{*}{$\begin{array}{l}\text { Difficulties } \\
\text { Easy }\end{array}$} & \multirow{2}{*}{$\begin{array}{l}\text { Details } \\
\text { Spelling puzzle game }\end{array}$} \\
\hline & 1 & 8 & Spelling & & \\
\hline Build your knowledge & 1 & 15 & Multiple-choice & Easy to medium & Like the win a million TV show \\
\hline Chakalaka & 1 & 20 & Multiple-choice & Easy to medium & Puzzle game \\
\hline Beekeeper & $1-3$ & 15 & Multiple-choice & Medium & Roll race game \\
\hline Baseball & $1-2$ & 30 & Multiple-choice & Medium to difficult & Using baseball game rules to answer questions \\
\hline Jeopardy & $1-3$ & 20 & Multiple-choice & Difficult & A quick answer race for $1-3$ learners \\
\hline
\end{tabular}

snake puzzle game, and turn-based Q\&A games. Each game involves 15-30 multiple choice question items pertaining to theories and concepts about human motivation (See Table 2). Quiz items in the WISC games were drawn from the assessment questions pool of 166 items about motivation in psychology.

https:/www.wisc-online.com/users/blendedlearning/games/ 33385/crossword

https://www.wisc-online.com/users/blendedlearning/games/ 33386/build-your-knowledge

https://www.wisc-online.com/users/blendedlearning/games/ 33388/chakalaka

https://www.wisc-online.com/users/blendedlearning/games/ 33391/baseball

https://www.wisc-online.com/users/blendedlearning/games/ 33395/beekeeper

https://www.wisc-online.com/users/blendedlearning/games/

33394/jeopardy

Using the same assessment questions pool of 166 items about motivation in psychology for building WISC-Online board games, a turn-base and competitive Q\&A game "Cell Game" was deployed for game-based learning:

\section{https://the-cell-game.com/cloud/play/}

$5 \mathrm{~d} 9 \mathrm{c} 8 \mathrm{~b} 253 \mathrm{fa} 2 \mathrm{e} 8001745 \mathrm{f} 6 \mathrm{ca}$

Apart from the game-based learning platform, a learning module was delivered to the students. Learning artefacts were based on an adaption of an open-source textbook on the psychology topic of motivation (https://courses.lumenlearning. com/wmopen-psychology/chapter/introduction-motivation/). A 23-page chapter of motivation consists of topics of motivation, self-efficacy, and mindset. The average reading time is around 25-30 min. Noted that all the interactive learning content in the original online textbook such as video links and self-assessments were removed.

Learning Outcome assessment. Regarding the learning outcome assessment quiz, a total of 15 questions were randomly selected from the question bank. Participants took the quiz through the Learning Management System by using the tablets after the $45 \mathrm{~min}$ session. The post-test was a closedbooked quiz and participants were not allowed to discuss with others during the test.

GREET07 Incentives: Describe any incentives or reimbursements provided to the learners.
Participants received credits on research participation towards completing an introductory level psychology course

GREET08 Instructors: For each instructor(s) involved in the educational intervention describe their professional discipline, teaching experience/expertise. Include any specific training related to the educational intervention provided for the instructor(s).

The game-based learning artefact and learning sequence was developed by a team led by an academic with expertize in blended learning, including recognition from university level award and international award such as the Reimagine Education.

GREET09 Delivery: Describe the modes of delivery (e.g., face-to-face, internet or independent study package) of the educational intervention. Include whether the intervention was provided individually or in a group and the ratio of learners to instructors.

Participants were guided to complete a 90-min session including briefing on the learning tasks, traditional learning with handouts on the topic of interest related to motivation, participating in the game-based learning tasks, then undertaking the learning outcomes assessments and survey on game-based learning constructs. Figure 1 entails the set up of the game-based learning sessions.

GREET10 Environment: Describe the relevant physical learning spaces (e.g., conference, university lecture theatre, hospital ward, community) where the teaching/learning occurred.

Learning sessions were conducted in an innovative classroom with mobile video walls and modular tables for group activities at a comprehensive university in Hong Kong. All participants completed the session face-to-face, with $50 \%$ of participants engaged the learning sequence individually while the other $50 \%$ of the participants completed the learning sequence in small groups of 3-4 members in each group.

GREET11 Schedule: Describe the scheduling of the educational intervention including the number of sessions, their frequency, timing and duration. 


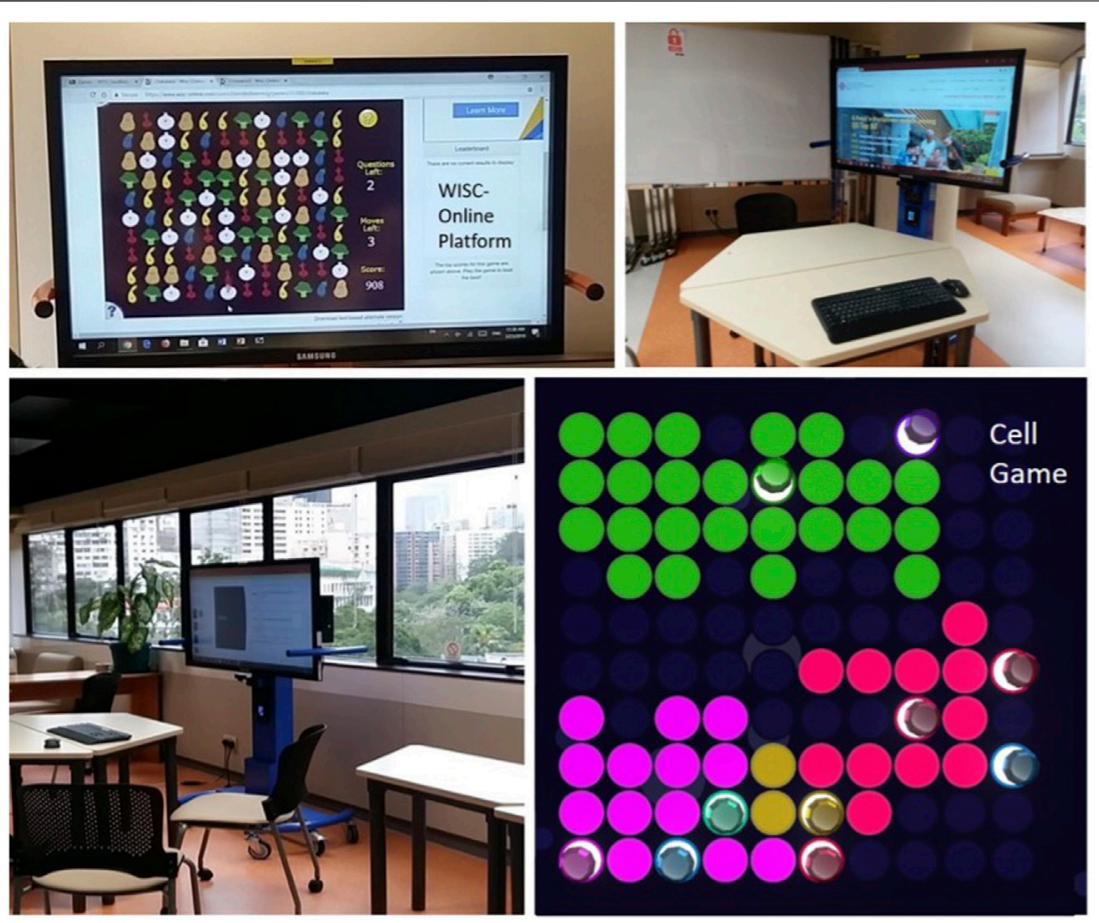

FIGURE 1 | Set up of game-based learning sessions.

GREET12 Describe the amount of time learners spent in face-to-face contact with instructors and any designated time spent in self-directed learning activities.

A one-off 90-min game-based learning session was administered to all participants between October and November 2019. All participating learners undertook a 90-min session with the following breakdown of activities:

Inform Consent and orientation on session procedures (10min) (Face-to-Face with game-based learning experimenters). Experiment Session (Self-Directed learning in group or individual formats).

(45-min).

Exercises/Revision (15-min).

Learning outcomes assessment and study survey (20-min).

GREET13 Did the educational intervention require specific adaptation for the learners? If yes, please describe the adaptations made for the learner(s) or group(s).

The game-based learning artefacts were specifically developed for the targeted learners. No adaptations were required.

GREET14 Was the educational intervention modified during the course of the study? If yes, describe the changes (what, why, when, and how).
No modification was made during the experimental period when the game-based learning sessions were administered.

GREET15 Attendance: Describe the learner attendance, including how this was assessed and by whom. Describe any strategies that were used to facilitate attendance.

This study features a total of 142 participants recruited from a pool of $600+$ learners enrolled in an introductory psychology course. Participants enrolled and completing this experimental session earn credits toward fulfilling their research participation requirements in the course. Participation in the learning sequence on "Motivation" was regarded as independent and studentinitiated learning on top of the definitive course curriculum. Similarly, learning assessment on "Motivation" unit incorporated in this study was not included in the summative course assessment of where the participants were recruited.

GREET16 Describe any processes used to determine whether the materials (item 5) and the educational strategies (item 6) used in the educational intervention were delivered as scheduled.

This game-based learning experiment was run over four sessions for all 142 participants. These sessions were administered on the same day with two experimenters giving orientations on the learning tasks and overseeing the experimental sessions. Two additional student helpers assisted in coordinating the learning sessions on logistics and clarification on work flow to participants. 


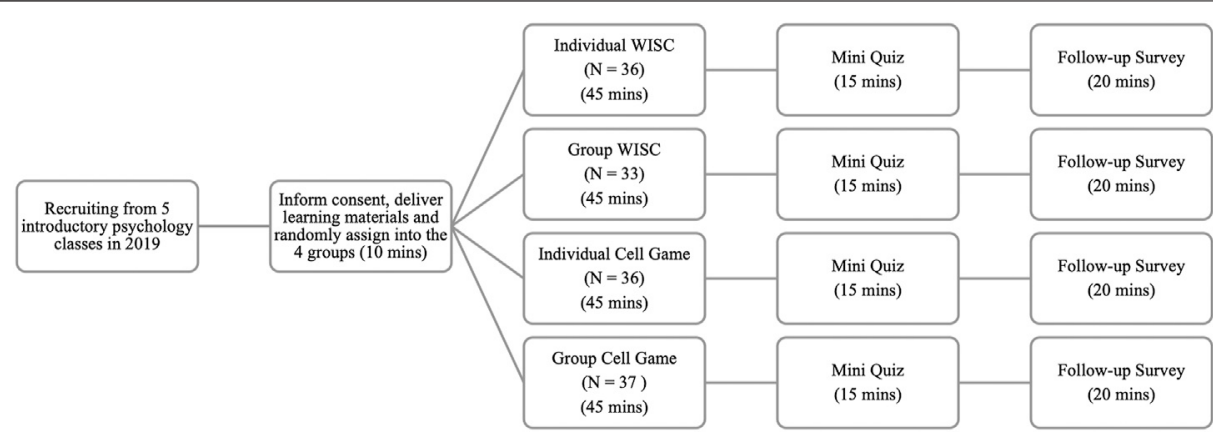

FIGURE 2 | Flow chart of the study procedure.

\begin{tabular}{lcc}
\hline TABLE 3 | Demographic information of the participants. & & \\
\hline Demographic information & N & \\
\hline Age & & \\
Mean & 18.8 & \\
Gender & & 47.8 \\
Female & 68 & 52.2 \\
Male & 74 & \\
Year of study & & 80.3 \\
First year & 114 & 16.9 \\
Second year & 24 & 1.4 \\
Third year & 2 & 1.4 \\
Fourth year & 2 & \\
Disciplines & & 54.2 \\
Business & 77 & 21.8 \\
Health and Social Sciences & 31 & 17.6 \\
Sciences, Technology and Engineering & 25 & 2.8 \\
Humanities, Design and Hotel Management & 4 & 3.5 \\
Others/not specified & 5 &
\end{tabular}

GREET17 Describe the extent to which the number of sessions, their frequency, timing and duration for the educational intervention was delivered as scheduled (item 11).

All learning sessions for this experiment on game-based learning was delivered as scheduled. A detailed flow chart was displayed in Figure 2.

\section{Data Analysis}

Demographic information including gender, year of the study, and the academic discipline of the participants were described with descriptives about learners' characteristics. To test the hypotheses set out in this study, we performed Two-way ANOVA to examine the main effects and interaction effects between learning format and competitiveness on participants' game flow experience. Participants who did not complete the follow-up questionnaire were excluded from the current analysis.

\section{Research Hypothesis}

4. There is significant difference of learning format on game flow experience.
5. There is significant difference of competitiveness on game flow experience.

6. There is interaction effect in game flow experience between learning format and competitiveness.

\section{RESULTS}

\section{Demographic Information}

Table 3 presented information about the 142 participants enrolled into the study. With a mean age of 18.8 years old, most of the participants $(80.3 \%)$ were 1 st year students. Majority of participants were recruited from the business discipline (54.2\%), followed by students from health \& social sciences (21.8), and STEM (17.6\%). Proportions of male (52.2\%) and female $(47.8 \%)$ participants were evenly distributed.

\section{Two-Way ANOVA on the eGame Flow}

A two-way ANOVA was performed to examine the effects of competitiveness game-based learning and learning format on the quiz performance and game flow outcomes. Table 4 presented the overall results of the Two-way ANOVA. Levene's Test indicated equal variances for all the domains except the Challenge $(F=2.76$, $p=0.05)$ and Goal Charity $(F=5.38, p=0.002)$.

Simple main effects analysis showed that learning in group reported significantly higher endorsement in Feedback $[F(1,138)=$ $\left.3.98, p=0.048, \eta^{2}=0.028\right]$, Goal Clarity $[F(1,138)=9.385, p=0.003$, $\left.\eta^{2}=0.064\right]$, and Social Interaction $\left[F(1,138)=23.573, p=0.000, \eta^{2}=\right.$ 0.146] than learning individually.

Regarding the test performance, a significance main effect of competitiveness was observed. Participants in the noncompetitive game-based learning condition with WISC games attained higher assesement total scores than their counterparts in the competitive game-based learning group $[F(1,138)=35.45$, $\left.p=0.01, \eta^{2}=0.06\right]$.

Interaction effects between learning format and competitiveness of game-based learning reached statistical significance for eGameFlow dimensions of Autonomy $\left[F(1,138)=4.137, p=0.044, \eta^{c}=0.029\right]$ and Goal Clarity $\left[F(1,138)=6.304, p=0.013, \eta^{2}=0.044\right]$ (see Figures 3, 4). Other eGameFlow dimensions, including concentration, feedback, challenge, immersion, social interaction, and knowledge 
TABLE 4 | Results of two-way ANOVA on learning outcomes and eGame flow.

Dependent Variables

Test performance

Learning format

Competitiveness

Learning format $\times$ competitiveness

Concentration

Learning format

Competitiveness

Learning format $\times$ competitiveness

Feedback

Learning format

Competitiveness

Learning format $\times$ competitiveness

Challenge

Learning format

Competitiveness

Learning format $\times$ competitiveness

Autonomy

Learning format

Competitiveness

Learning format $\times$ competitiveness

Goal clarity

Learning format

Competitiveness

Learning format $\times$ competitiveness Immersion

Learning format

Competitiveness

Learning format $\times$ competitiveness

Social interaction

Learning format

Competitiveness

Learning format $\times$ competitiveness

Knowledge improvement

Learning format

Competitiveness

Learning format $\times$ competitiveness

SS $d f \quad$ MS

\section{MS}

0.11

35.45

0.49

35.45

0.49

3.24

0.48

1.05

3.94

0.61

0.14

3.21

1.62

3.00

4.23

4.26

4.76

10.81

3.28

7.26

2.55

3.36

0.00

37.84

0.25

3.50

0.02

0.48

0.14
$\boldsymbol{F}$

p

Bonferroni

$\eta^{2}$

$0.02-0.88$

$8.06 \quad 0.01$

$\begin{array}{ll}0.112 & 0.74\end{array}$

Non-competitive > competitive

0.06

$\begin{array}{ll}3.24 & 0.07\end{array}$

$0.48 \quad 0.48$

$1.09 \quad 0.30$

$3.98 \quad 0.048$

$0.61 \quad 0.44$

$0.15 \quad 0.70$

$2.43 \quad 0.12$

$1.22 \quad 0.27$

$2.27 \quad 0.13$

$3.68 \quad 0.06$

$3.70 \quad 0.06$

$\begin{array}{ll}4.14 & 0.04\end{array}$

$9.39 \quad 0.00$

$2.85 \quad 0.09$

$6.30 \quad 0.01$

$2.49 \quad 0.12$

$3.28 \quad 0.07$

$0.00 \quad 0.96$

$23.57 \quad 0.00$

$0.16 \quad 0.69$

$\begin{array}{ll}2.18 & 0.14\end{array}$

Group > Individual

Group > individual

0.00

0.01

0.03

0.00

0.00

0.02

0.01

0.02

0.03

0.03

0.03

Group > Individual $\quad 0.06$

0.02

0.04

0.02

0.02

0.00

0.15

0.00

0.02

0.00

0.00

0.00

Italics in this table refers to names of dependent variables being tested.
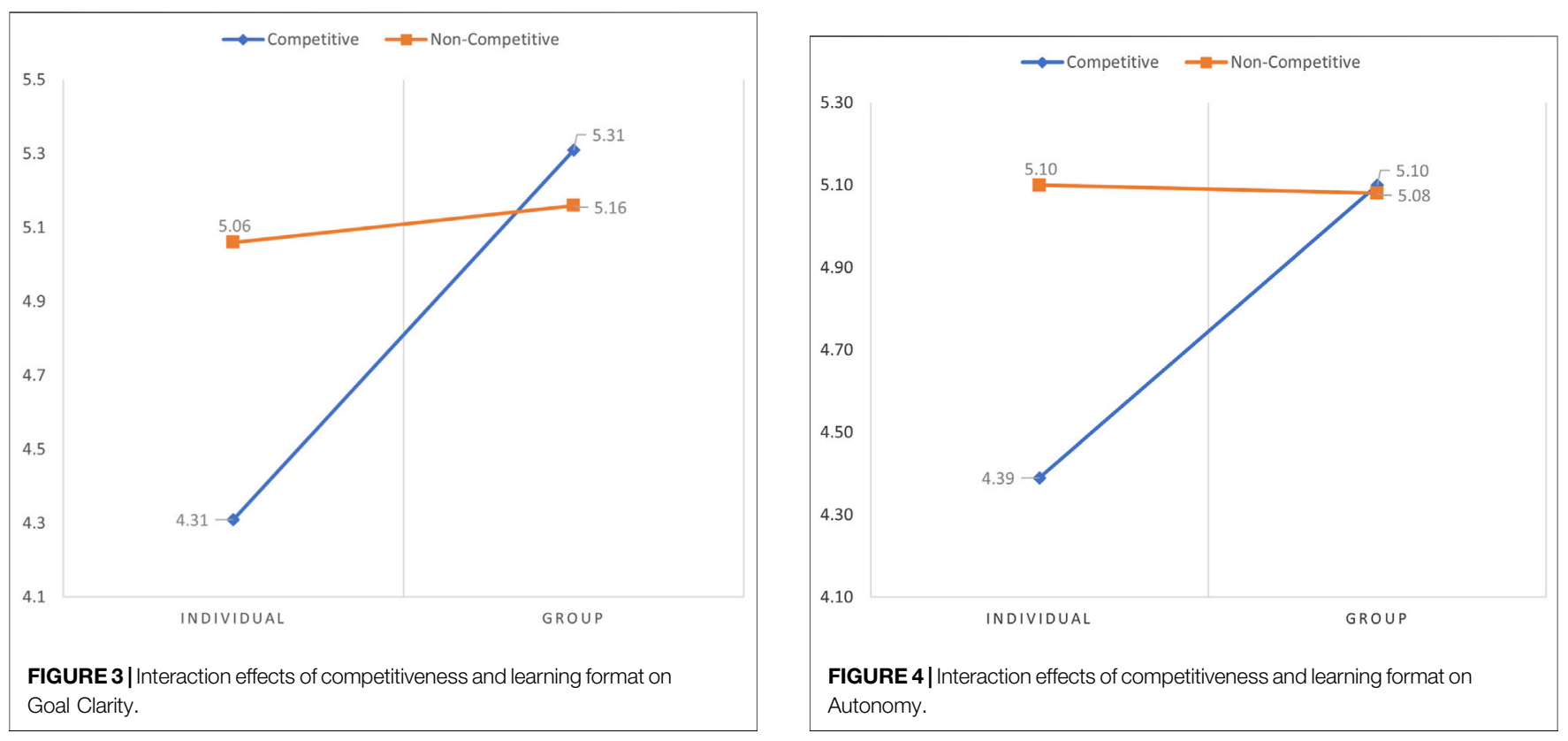

Frontiers in Education | www.frontiersin.org 
improvement, did not reveal statistically significant interaction effects.

\section{DISCUSSION}

Results in this study suggested that game-based learning, when adopting non-competitive games in a group format for learning psychology at the undergraduate level, would likely yield higher enhancement in terms of learning outcome. Learners experienced a heightened level of reported goal clarity and autonomy with non-competitive games when game-based learning was administered individually, rather than in a group format. Heightened flow dimensions observed in the individual rather than the group game format contradicted with previous findings about benefit of ad-hoc group learning in large classes (Tomcho and Foels, 2012). We hypothesized that the observed flow among learners on individual game-based learning was facilitated by the format and nature of learning theoretical concepts related to motivation in the current study. Adopting the cognitive load theory on game-based learning, individual board games introduce minimal extraneous cognitive load on learners when compared with other turn-based competitive games or immersive competitive games (Fisch, 2017).

While some game flow variables significantly affecting learning outcomes, only cognitive dimensions in the featured game flow model in feedback, goal clarity, and social interaction exhibited statistically significant effects. Most of the affective dimensions in the game flow model that align with positive valence and affect, including challenge, and immersion, did not reach statistical significance in the current findings. The sole exception was the significant interaction effect on autonomy, in which perceived autonomy was low in the competitive and territorial Cell Game when administered individually, but matched its non-competitive counterpart in the WISC-Online quiz game condition when learners in Cell Game were in a group competition format. Interaction effects observed in this study do not resonate with previous evidence arguing for equivalence between administering game-based learning in solitary and collaborative modes (Chen et al., 2015; Van Der Meij et al., 2011).

While immersion has been regarded as a major factor in gamebased learning toward learners' engagement (Krassmann et al., 2017; Hamari et al., 2016; Cheng et al., 2017), the lack of significant effect observed on immersion in the current study could be attributed to the trivia/quiz game format adopted in this study instead of designing a serious game for learning about motivation. Cheng (Cheng et al., 2017) suggested that though serious games activates immersion, yet immersion does not necessarily warrant learning gain. Indeed, immersion may influence learning indirectly as a prerequisite to game mastery, which subsequently leads to learning gain.

Reported prevalence of emphasizing cognitive dimensions in game flow for game-based learning echoed the dominance of achievement orientations in performance approach and performance avoidance, while undermining mastery goal that associated with affective outcomes and engagement toward intrinsic motivation of learning (Chen and Wong, 2015a, 2015b; Wang and Rao, 2020).

While participants in this study feature predominantly Chinese learners in their adolescence and early adulthood, findings from this study suggest that in application of gamebased learning on academic knowledge, design and implementation of game-based learning should consider game flow dimensions that enhances the both cognitive and affective domains in learning experience. Nonetheless, affordances for affective experience from game-based learning (e.g., immersion, concentration, challenge, autonomy) in the context of knowledge-oriented learning may be secondary when compared with use of game-based learning in other types of experiential learning involving more affective components, such as service learning (Giles and Eyler, 1994) and intra-personal development.

For theoretical concept learning featured in this study, these considerations on affective components of game-based learning tend to be undermined by performance-related, cognitive dimensions in game flow such as goal clarity (i.e., how can I benefit from this game on mastering the academic subject matter), feedback (i.e., is this game helping me in identifying my strength and weaknesses mastering or applying the academic subject matter), and social interaction (i.e., is this game-based learning allowing me to solve problems collaboratively through team-based learning).

These performance-centric orientations derived from the current study corroborate with some proposed utility of gamebased learning in "performance monitoring" and "social learning" (Westera, 2015). It is also hypothesized to align with the Asian pragmatic orientation toward leveraging game-based learning toward academic achievement (So and Seo, 2018). In addition, performance approach goal orientation in using gamebased learning to enhance undergraduate learning, as reflected in corresponding game flow dimensions, offers a stark contrast to K12 sector counterparts with conventional conception of gamebased learning mostly enhancing enjoyment and engagement throughout the learning process (Chang et al., 2017).

\section{LIMITATIONS}

Though trivia/quiz format game-based learning has been suggested to be instrumental for enhancing theoretical knowledge mastery (Ranieri et al., 2018), learning related to applications and problem-solving were not examined in the current study with reference to the scope of this proposed study and keeping the experimental session viable for our participating learners. Further studies could introduce learning tasks of different natures toward generalizing the effect of gamebased learning in varying learning context.

With focus on flow of game-based learning and subsequent changes on learning performance, the current study did not address the role of other integral psychological mechanisms, such as intrinsic motivation (Hanus and Fox, 2015; Sailer et al., 2017; Chapman and Rich, 2018) and cognitive load (Chang et al., 2017; Fisch, 2017) involved in the translation of 
game-based learning to learning enhancement. Further studies incorporating flow, motivation, and cognitive load would allow a comprehensive framework for examining the underlying psychological mechanisms of game-based learning, as well as their relations and reciprocal synergy with each other.

\section{CONCLUSION}

Results from this study employing experimental design offer evidence for positive effect of using game-based learning in undergraduate education context. Specifically, non-competitive game-based learning, when performed in groups, was suggested to promote better learning outcomes. Game flow dimensions related to cognitive domains in game-based learning, specifically goal clarity, feedback, and social interaction, has been demonstrated to have interaction effect on learning outcomes, while affective domains in game-based learning were undermined by performance achievement orientation among Asian learners. Affective elements with enjoyment and thrill, as conceptualized in challenge and immersion by the game flow model, may not align well with the prevailing performance orientation in Asian academia context. The use of game-based learning in knowledge-oriented learning in the Asian context could be optimized by focusing on utility of game-based learning toward performance monitoring and social learning.

\section{DATA AVAILABILITY STATEMENT}

The original contributions presented in the study are included in the article/Supplementary Material, further inquiries can be directed to the corresponding author.

\section{REFERENCES}

Abramson, C. I., Burke-Bergmann, A. L., Nolf, S. L., and Swift, K. (2009). Use of Board Games, Historical Calendars, and Trading Cards in a History of Psychology Class. Psychol. Rep. 104 (2), 529-544. doi:10.2466/PR0.104.2. 529-544

Anderson, L. W., Krathwohl, D. R., and Bloom, B. S. (2001). A Taxonomy for Learning, Teaching, and Assessing: A Revision of Bloom's Taxonomy of Educational Objectives. London: Longman.

Berrenberg, J. L., and Prosser, A. (1991). The Create-A-Game Exam: A Method to Facilitate Student Interest and Learning. Teach. Psychol. 18 (3), 167-169. doi:10. 1207/s15328023top1803_9

Cairns, P. (2016). "Engagement in Digital Games," in Why Engagement Matters: Cross-Disciplinary Perspectives of User Engagement in Digital Media. Editors H. O’Brien and P. Cairns (Berlin: Springer International Publishing), 81-104. doi:10.1007/978-3-319-27446-1_4

Chang, C.-C., Liang, C., Chou, P.-N., and Lin, G.-Y. (2017). Is Game-Based Learning Better in Flow Experience and Various Types of Cognitive Load Than Non-game-based Learning? Perspective from Multimedia and media Richness. Comput. Hum. Behav. 71, 218-227. doi:10.1016/j.chb.2017.01.031

Chapman, J. R., and Rich, P. J. (2018). Does Educational Gamification Improve Students' Motivation? if So, Which Game Elements Work Best? J. Edu. Business 93 (7), 315-322. doi:10.1080/08832323.2018.1490687

Chen, C. H., Wang, K. C., and Lin, Y. H. (2015). The Comparison of Solitary and Collaborative Modes of Game-Based Learning on Students' Science Learning

\section{ETHICS STATEMENT}

The studies involving human participants were reviewed and approved by The Hong Kong Polytechnic University. The patients/participants provided their written informed consent to participate in this study.

\section{AUTHOR CONTRIBUTIONS}

All authors have contributed equally on data collection, data analysis, and manuscript writing.

\section{FUNDING}

The presented study was funded by the University Grants Committee (UGC) of Hong Kong under the Teaching and Learning Related Project (Project Ref: UGC-89LT), "Developing Multidisciplinary and Multicultural Competences through Gamification and Challenge-Based Collaborative Learning". (https://www.ugc.edu.hk/eng/ugc/ activity/teach_learn/teach/triennium1619. html).

\section{ACKNOWLEDGMENTS}

The authors would like to express appreciation for WiscOnline, a non-profit organization that provides an online platform for creating educational board games (https://www. wisc-online.com/); and the University Grants Committee (UGC) of Hong Kong that funded the project leading to this study.

and Motivation. Educ. Tech. Soc. 18 (2), 237-248. doi:10.4018/978-1-52256026-5

Chen, W.-W., and Wong, Y.-L. (2015b). Chinese Mindset: Theories of Intelligence, Goal Orientation and Academic Achievement in Hong Kong Students. Educ. Psychol. 35 (6), 714-725. doi:10.1080/01443410.2014.893559

Chen, W.-W., and Wong, Y.-L. (2015a). The Relationship between Goal Orientation and Academic Achievement in Hong Kong: The Role of Context. Asia-pacific Edu Res. 24 (1), 169-176. doi:10.1007/s40299-013-0169-7

Cheng, M.-T., Lin, Y.-W., She, H.-C., and Kuo, P.-C. (2017). Is Immersion of Any Value? whether, and to what Extent, Game Immersion Experience during Serious Gaming Affects Science Learning. Br. J. Educ. Technol. 48 (2), 246-263. doi:10.1111/bjet.12386

Csikszentmihalyi, M. (2014). Flow and the Foundations of Positive Psychology. Berlin: Springer. doi:10.1007/978-94-017-9088-8

De-Marcos, L., Garcia-Lopez, E., and Garcia-Cabot, A. (2016). On the Effectiveness of Game-like and Social Approaches in Learning: Comparing Educational Gaming, Gamification \& Social Networking. Comput. Edu. 95, 99-113. doi:10. 1016/j.compedu.2015.12.008

Erhel, S., and Jamet, E. (2019). Improving Instructions in Educational Computer Games: Exploring the Relations between Goal Specificity, Flow Experience and Learning Outcomes. Comput. Hum. Behav. 91, 106-114. doi:10.1016/j.chb. 2018.09.020

Fisch, S. M. (2017). "Bridging Theory and Practice: Applying Cognitive and Educational Theory to the Design of Educational Media," in Cognitive Development in Digital Contexts (Amsterdam: Elsevier), 217-234. doi:10. 1016/B978-0-12-809481-5.00011-0 
Fu, F.-L., Su, R.-C., and Yu, S.-C. (2009). EGameFlow: A Scale to Measure Learners' Enjoyment of E-Learning Games. Comput. Edu. 52, 101-112. doi:10.1016/j. compedu.2008.07.004

Giles, D. J., and Eyler, J. (1994). The Theoretical Roots of Service-Learning in John Dewey: Toward a Theory of Self-Learning. Mich. J. Community Serv. Learn. 1 (1), 77-85. doi:10.1057/9781137383259.0005

Goldey, K. L., and Espinosa, A. (2020). Sculptorades, Cloodles, and Cameos, Oh My! A Cranium Game for General Psychology. Teach. Psychol. 14, 33. doi:10. $1177 / 0098628320979877$

Hamari, J., and Koivisto, J. (2014). Measuring Flow in Gamification: Dispositional Flow Scale-2. Comput. Hum. Behav. 40, 133-143. doi:10.1016/j.chb.2014.07.048

Hamari, J., Shernoff, D. J., Rowe, E., Coller, B., Asbell-Clarke, J., and Edwards, T. (2016). Challenging Games Help Students Learn: An Empirical Study on Engagement, Flow and Immersion in Game-Based Learning. Comput. Hum. Behav. 54, 170-179. doi:10.1016/j.chb.2015.07.045

Hanus, M. D., and Fox, J. (2015). Assessing the Effects of Gamification in the Classroom: A Longitudinal Study on Intrinsic Motivation, Social Comparison, Satisfaction, Effort, and Academic Performance. Comput. Edu. 80, 152-161. doi:10.1016/j.compedu.2014.08.019

Hou, H.-T. (2015). Integrating Cluster and Sequential Analysis to Explore Learners' Flow and Behavioral Patterns in a Simulation Game with Situated-Learning Context for Science Courses: A Video-Based Process Exploration. Comput. Hum. Behav. 48, 424-435. doi:10.1016/j.chb.2015.02.010

Howard-Jones, P. A., and Jay, T. (2016). Reward, Learning and Games. Curr. Opin. Behav. Sci. 10, 65-72. doi:10.1016/j.cobeha.2016.04.015

Kasurinen, J., and Knutas, A. (2018). Publication Trends in Gamification: A Systematic Mapping Study. Comput. Sci. Rev. 27, 33-44. doi:10.1016/j. cosrev.2017.10.003

Kiili, K. (2005). On Educational Game Design: Building Blocks of Flow Experience on Educational Game Design. Berlin: Springer.

Koivisto, J., and Hamari, J. (2019). The Rise of Motivational Information Systems: A Review of Gamification Research. Int. J. Inf. Manag. 45, 191-210. doi:10. 1016/J.IJINFOMGT.2018.10.013

Krassmann, A. L., Falcade, A., Bernardi, G., and Medina, R. D. (2017). Exploring Student's Motivational Aspects by Developing and Applying a Ubiquitous Digital Serious Game Approach. Ce 08, 405-430. doi:10.4236/ce.2017.83032

Licorish, S. A., Owen, H. E., Daniel, B., and George, J. L. (2018). Students' Perception of Kahoot!'s Influence on Teaching and Learning. Rptel 13, 121. doi:10.1186/s41039-018-0078-8

Nah, F. F. H., Eschenbrenner, B., Zeng, Q., Telaprolu, V. R., and Sepehr, S. (2014). Flow in Gaming: Literature Synthesis and Framework Development. Ijisam 1 (1/2), 83-124. doi:10.1504/IJISAM.2014.062288

Nakamura, J., and Csikszentmihalyi, M. (2014). "The Concept of Flow," in Flow and the Foundations of Positive Psychology (Berlin: Springer), 239-263. doi:10. 1007/978-94-017-9088-8_16

Paul, S. T., Hollis, A. M., and Messina, J. A. (2006). A Technology Classroom Review Tool for General Psychology. Teach. Psychol. 33 (4), 276-279. doi:10. 1207/s15328023top3304_8

Phillips, A. C., Lewis, L. K., McEvoy, M. P., Galipeau, J., Glasziou, P., Moher, D., et al. (2016). Development and Validation of the Guideline for Reporting Evidence-Based Practice Educational Interventions and Teaching (GREET). BMC Med. Educ. 16 (1), 237. doi:10.1186/s12909-016-0759-1

Plass, J. L., Homer, B. D., and Kinzer, C. K. (2015). Foundations of Game-Based Learning. Educ. Psychol. 50 (4), 258-283. doi:10.1080/00461520.2015.1122533
Ranieri, M., Raffaghelli, J. E., and Bruni, I. (2018). Game-based Student Response System: Revisiting its Potentials and Criticalities in Large-Size Classes. Active Learn. Higher Edu. 13, 132. doi:10.1177/1469787418812667

Reiners, T., and Wood, L. C. (2015). Gamification in Education and Business. London: Gamification in Education and Business, 1-710. doi:10.1007/978-3319-10208-5

Sailer, M., Hense, J. U., Mayr, S. K., and Mandl, H. (2017). How Gamification Motivates: An Experimental Study of the Effects of Specific Game Design Elements on Psychological Need Satisfaction. Comput. Hum. Behav. 69, 371-380. doi:10.1016/j.chb.2016.12.033

Sailer, M., and Homner, L. (2019). The Gamification of Learning: a Meta-Analysis. Educ. Psychol. Rev. 32, 77-112. doi:10.1007/s10648-019-09498-w

Sedig, K. (2007). Toward Operationalization of 'flow' in Mathematics Learnware. Comput. Hum. Behav. 23 (4), 2064-2092. doi:10.1016/j.chb. 2006.11.001

Shin, N. (2006). Online Learner's 'flow' Experience: an Empirical Study. Br. J. Educ. Tech. 37 (5), 705-720. doi:10.1111/j.1467-8535.2006.00641.x

So, H.-J., and Seo, M. (2018). "A Systematic Literature Review of Game-Based Learning and Gamification Research in Asia," in Routledge International Handbook of Schools and Schooling in ASIA. Editors K. J. Kennedy and J. C.-K. Lee (Upper Saddle River: Routledge), 396-418. doi:10.4324/ 9781315694382-37

Stansbury, J. A., and Earnest, D. R. (2017). Meaningful Gamification in an Industrial/Organizational Psychology Course. Teach. Psychol. 44 (1), 38-45. doi:10.1177/0098628316677645

Sweetser, P., and Wyeth, P. (2005). "GameFlow: A Model for Evaluating Player Enjoyment in Games," in ACM Computers in Entertainment. London: ACM Press. doi:10.1145/1077246.1077253

Terras, M. M., and Boyle, E. A. (2019). Integrating Games as a Means to Develop Elearning: Insights from a Psychological Perspective. Br. J. Educ. Technol. 50 (3), 1049-1059. doi:10.1111/bjet.12784

Tomcho, T. J., and Foels, R. (2012). Meta-Analysis of Group Learning Activities: Empirically Based Teaching Recommendations. Teach. Psychol. 39 (3), 159-169. doi:10.1177/0098628312450414

Van Der Meij, H., Albers, E., and Leemkuil, H. (2011). Learning from Games: Does Collaboration Help? Br. J. Educ. Tech. 42 (4), 655-664. doi:10.1111/j.1467-8535. 2010.01067.x

Wang, J., and Rao, N. (2020). What Do Chinese Students Say about Their Academic Motivational Goals-Reasons Underlying Academic Strivings? Asia Pac. J. Edu. 12, 1-15. doi:10.1080/02188791.2020.1812513

Westera, W. (2015). Games Are Motivating, Aren't They? Disputing the Arguments for Digital Game-Based Learning. Ijsg 2 (2), 47. doi:10.17083/ ijsg.v2i2.58

Conflict of Interest: The authors declare that the research was conducted in the absence of any commercial or financial relationships that could be construed as a potential conflict of interest.

Copyright $\odot 2021$ Chan, Wan and King. This is an open-access article distributed under the terms of the Creative Commons Attribution License (CC BY). The use, distribution or reproduction in other forums is permitted, provided the original author(s) and the copyright owner(s) are credited and that the original publication in this journal is cited, in accordance with accepted academic practice. No use, distribution or reproduction is permitted which does not comply with these terms. 